\title{
IDENTIFICAZIONE RAPIDA DI CEPPI DI CITOMEGALOVIRUS UMANO \\ FARMACO-RESISTENTI MEDIANTE nPCR-RFLP IN SOGGETTI SOTTOPOSTI A TRAPIANTO.
}

Medici M.C.,Aloisi A., Martinelli M,Abelli L.A., Dettori G. e Chezzi C.

Sezione di Microbiologia

- Dipartimento di Patologia e Medicina di Laboratorio

- Università degli Studi di Parma

- Viale A. Gramsci, 14 - 43100 Parma.

Introduzione. È noto che la terapia con ganciclovir (GCV) o acyclovir (ACV) nell'infezione da citomegalovirus umano (HCMV) può fallire per l'insorgenza di mutazioni sul gene UL97.

Metodi. Per identificare le mutazioni di HCMV-UL97 M460V, H520Q, C592G, A594V, L595F/S e C603W associate a farmaco-resistenza, è stata allestita un'nPCR-RFLP che impiega primer ed enzimi descritti in letteratura per l'amplificazione di 4 frammenti genomici e la loro digestione, rispettivamente. Come controllo "wild-type" (wt) sono stati utilizzati HCMV-AD169 e HCMV-Towne. L'nPCRRFLP è stata applicata su 24 sieri/plasma HCMV-DNA positivi (range $<600-83.000$ copie $/ \mathrm{ml}$ ) appartenenti a 22 pazienti ( 15 con trapianto di rene, 6 di midollo e 1 di rene e pancreas). Tredici soggetti non avevano assunto GCV o ACV (gruppo di controllo) e 9 erano stati sottoposti a profilassi orale con questi farmaci (gruppo di studio).

Risultati. Nel gruppo di controllo l'nPCR-RFLP ha consentito di caratterizzare in 8 casi $(61,5 \%) 6$ codoni e in 1 caso $(7,7 \%) 4$ codoni. Tutti sono risultati wt. In 4 casi $(30,8 \%)$ l'nPCR non ha amplificato alcun frammento.

$\mathrm{Nel}$ gruppo di studio l'nPCR-RFLP ha identificato in 6 casi $(66,7 \%)$ tutti i codoni, in 2 casi $(22,2 \%) 3$ codoni ed in un caso $(11,1 \%)$ ha dato esito negativo sul primo campione ed ha identificato 4 codoni sul secondo. Di questi pazienti, uno presentava HCMV mutato nel codone 460 e wt negli altri 5. La mutazione M460V all'nPCR-RFLP è stata confermata mediante sequenziamento.

Conclusioni. Il tasso di ceppi di HCMV con mutazioni farmaco-indotte da noi rivelato in pazienti sottoposti a trapianto e profilassi con GCV o ACV conferma il dato ottenuto in altri studi. L'nPCR-RFLP sembra un metodo rapido e di esecuzione semplice per identificare le principali mutazioni di HCMV-UL97. L'incompleta caratterizzazione dei codoni in alcuni casi e l'assenza di amplificazione in altri potrebbero dipendere dalla bassa concentrazione virale e/o da mutazioni nel sito di attacco dei primer. 